\title{
Electrosynthesis of hydrogen peroxide in a filter-press flow cell using graphite felt as air-diffusion cathode
}

\author{
Tzayam Pérez $^{\mathrm{a}, 1}$, Gabriela Coria ${ }^{\mathrm{b}}$, Ignasi Sirés ${ }^{\mathrm{c}, 1}$, José L. Nava ${ }^{\mathrm{b}, *}, 1$, Agustín R. Uribe ${ }^{a}$ \\ a Universidad de Guanajuato, Departamento de Ingeniería Química, División de Ciencias Naturales y Exactas, Noria Alta S/N, C.P. 36050 Guanajuato, Guanajuato, Mexico \\ ${ }^{\mathrm{b}}$ Departamento de Ingeniería Geomática e Hidráulica, Universidad de Guanajuato, Av. Juárez 77, Zona Centro, C.P. 36000 Guanajuato, Guanajuato, Mexico \\ c Laboratori d'Electroquímica dels Materials i del Medi Ambient, Departament de Química Física, Facultat de Química, Universitat de Barcelona, Martí i Franquès 1-11, \\ 08028 Barcelona, Spain
}

\section{A R T I C L E I N F O}

\section{Keywords:}

Electrosyn thesis

Filter-press cell

Gas-diffusion electrode

Graphite felt

Hydrogen peroxide

Oxygen reduction reaction

\section{A B S T R A C T}

The electrosynthesis of $\mathrm{H}_{2} \mathrm{O}_{2}$ via $\mathrm{O}_{2}$ reduction was feasible employing cheap, unmodified graphite felt on top of carbon cloth as air-diffusion cathode fitted into an undivided filter-press cell. The experiments were performed in a pre-pilot plant with recirculation of $4 \mathrm{dm}^{3}$ of $0.05 \mathrm{M} \mathrm{Na}_{2} \mathrm{SO}_{4}$ solutions at pH3.0 upon continuous air feeding to the cathode. The $\mathrm{H}_{2} \mathrm{O}_{2}$ electrogeneration occurred within the range $-0.30 \leq E \leq-0.01 \mathrm{~V} \mid$ SHE, being dependent on the mean linear flow velocity $(u)$, which is related to the mass transport of hydronium ions. Optimum conditions achieved at $E=-0.30 \mathrm{~V} \mid \mathrm{SHE}$ and $u=27.4 \mathrm{~cm} \mathrm{~s}^{-1}$ yielded $100.4 \mathrm{mg} \mathrm{dm}^{-3} \mathrm{H}_{2} \mathrm{O}_{2}$, with efficiency close to $100 \%$ and low energy consumption.

\section{Introduction}

Hydrogen peroxide is listed as one of the 100 most important chemicals in the world, being involved in a large range of industrial applications [1], including water treatment via advanced oxidation processes like $\mathrm{H}_{2} \mathrm{O}_{2} / \mathrm{O}_{3}, \mathrm{H}_{2} \mathrm{O}_{2} / \mathrm{UVC}$ and $\mathrm{H}_{2} \mathrm{O}_{2} / \mathrm{Fe}^{2+}$ or electrochemical methods such as electrooxidation, electro-Fenton and photoelectro-Fenton at acidic $\mathrm{pH} \sim 3.0$ [2]. Hydrogenation of alkyl-9,10anthraquinone followed by autooxidation in the presence of $\mathrm{O}_{2}$ is the leading technology for industrial synthesis [3], although co-generation of exhaust gas, toxic liquid and solid waste is a major concern.

The direct electrochemical $\mathrm{H}_{2} \mathrm{O}_{2}$ sy nthesis appears as a much greener method. It is less energy-intensive, especially if coupled with renewable energy sources, than the chemical alternatives and allows minimizing risks and costs. Actually, it is a zero waste strategy because it can be tailored to produce only the required amount of chemical just by controlling the electrolysis conditions.
Two main electrolytic approaches have prevailed for the twoelectron oxygen reduction reaction (ORR) from air or pure $\mathrm{O}_{2}$ : (i) feeding of a gas-diffusion electrode (GDE), and (ii) direct sparging into the electrolyte. The ORR can occur in acidic and alkaline media [4]:

$$
\begin{aligned}
& \mathrm{O}_{2}+2 \mathrm{H}^{+}+2 \mathrm{e}^{-} \\
& \rightarrow \mathrm{H}_{2} \mathrm{O}_{2} \\
& =0.695 \mathrm{~V} \\
& \text { I SHE } \\
& \begin{aligned}
\mathrm{O}_{2}+\mathrm{H}_{2} \mathrm{O}+2 \mathrm{e}^{-} & \rightarrow \mathrm{HO}_{2}^{-}+\mathrm{OH}^{-} \\
& =-0.065 \mathrm{~V} \\
& \mid \mathrm{SHE}
\end{aligned}
\end{aligned}
$$

Carbonaceous materials act as optimum cathodes for $\mathrm{H}_{2} \mathrm{O}_{2}$ electrogeneration owing to their high stability, conductivity, resistance, non-toxicity and low cost [5]. In the first approach, GDEs are most

\footnotetext{
* Corresponding author.

Email addresses: t.perezsegura@ugto.mx (T. Pérez); g.coriarodriguez@ugto.mx (G. Coria); i.sires@ub.edu (I. Sirés); jlnm@ugto.mx (J.L. Nava); uribe@ ugto.mx (A.R. Uribe)
}

ISE Active Member. 
usually prepared from raw carbon black mixed with PTFE to impart hydrophobicity [6-10]. They yield the highest amount of $\mathrm{H}_{2} \mathrm{O}_{2}$ thanks to both, the existence of a triple phase boundary (TPB) and pressurization, which favor the two-electron ORR over the HER. This, in turn, shifts the cathode potential to more positive values [3]. Significant efforts are spent to simultaneously increase the activity, selectivity and stability of electrocataly sts by modifying the carbon particles with quinones, Pd-Au or Co-based compounds [11-13]. Nonetheless, GDEs present some drawbacks: (i) complex setups needed to prevent flooding; (ii) costly commercial cathode materials; and (iii) modest mechanical resistance.

Following the second approach, a lower $\mathrm{H}_{2} \mathrm{O}_{2}$ concentration is attained due to limited solubility of gaseous $\mathrm{O}_{2}$ and mass transport limitations, which could be a disadvantage for some industrial applications but not for water treatment. However, simpler setups and less strict control are required, and materials are usually cheaper. The greatest $\mathrm{H}_{2} \mathrm{O}_{2}$ contents are obtained with three-dimensional carbons like graphite felt [14-16], reticulated vitreous carbon [15], fibers [17], nanotubes [18], hierarchically porous carbon [19] and graphene [20]. Modification of the setup or reactor has also been addressed: (i) greater mass transport of $\mathrm{O}_{2}$ toward the cathode surface can be promoted with a rotating cylinder electrode thanks to the turbulent regime [21], whereas (ii) super-saturation of $\mathrm{O}_{2}$ can be fostered at ambient pressure with a jet aerator [22] or at high pressure reactors [23]. The main drawbacks of these latter systems are the supply of dirty air that poisons the cathode, the high mechanical stress undergone by the 3D carbon or the high cost of pressurization.

In this work, a novel approach has been followed for the $\mathrm{H}_{2} \mathrm{O}_{2}$ electrogeneration from reduction of $\mathrm{O}_{2}$ at constant potential in $4 \mathrm{dm}^{3}$ of $0.05 \mathrm{M} \mathrm{Na}_{2} \mathrm{SO}_{4}$ solutions at $\mathrm{pH} 3.0$ using a pre-pilot flow plant. Commercial carbon cloth has been hydrophobized and put in contact with raw graphite felt to convert a 3D cathode into an efficient GDE by increasing the electrochemical contact area and fav oring the mass transport inside the porous material. Air was supplied through a chamber added to an undivided FM01-LC flow cell. The cathode potential and liquid flow rate were evaluated as main operation parameters.

\section{Materials and methods}

Analy tical grade reagents from Sigma-Aldrich and Fermont and deionized water were employed. The characteristics of the FM01LC filter-press reactor can be found elsewhere [24]. Here, the conventional undivided FM01-LC reactor, which was modified to include an air chamber (Fig. 1a), was equipped with a Ti|Pt plate anode manufactured following the Pechini method and a stainless steel frame ( $4 \mathrm{~cm}$ height, $16 \mathrm{~cm}$ length, $0.30 \mathrm{~cm}$ thickness) for the electrical supply to the cathode. A novel GDE as cathode was assembled by using a commercial carbon cloth of $64 \mathrm{~cm}^{2}$ area, which was hydrophobized with PTFE $[7,25]$, on top of which a graphite felt parallelepiped $(4 \mathrm{~cm}$ height $\times 16 \mathrm{~cm}$ length $\times 0.15 \mathrm{~cm}$, $10-100 \times 10^{-3} \Omega^{-1} \mathrm{~cm}^{-1}$ electrical conduc tiv ity, $651 \mathrm{~cm}^{2} \mathrm{~cm}^{-3} \mathrm{vol}-$ umetric area, 0.97 porosity) was placed without any glue. The thickness of the strands was $19 \mu \mathrm{m}$. It is important to remark that the pressure exerted by the filter-press and the turbulence promoters was high enough so as to ensure a reasonable electrical contact. The cloth and graphite felt were from ROOE Group. The GDE was in contact with the air chamber fed with atmospheric air (Dewalt D55168 air compressor) under overpressure of $0.7 \mathrm{bar}$ regulated with a gauge back-pressure to electrogenerate $\mathrm{H}_{2} \mathrm{O}_{2}$. Two plastic routed meshes (promoters type D) were used [24], one between the anode and cathode and the other into the air chamber.
To provide a constant liquid flow through the plant under recirculation batch mode, a magnetic pump and a flowmeter were installed (Fig. 1b). All trials were made at constant cathode potential provided by a BK Precision 1621A power source, which directly displayed the potential difference between the anode and cathode $\left(E_{\text {cell }}\right)$. The electrode potentials were measured against a saturated sulfate reference electrode (SSE), inserted into a Luggin capillary, using an Agilent 34,410 high impedance multimeter. All electrode potentials are referred to standard hy drogen electrode (SHE).

In our previous study [15], the reduction of dissolved $\mathrm{O}_{2}$ for mass-transp ort controlled $\mathrm{H}_{2} \mathrm{O}_{2}$ electrogeneration at graphite felt in sulfate occurred within the domain $-0.40<E<-0.10 \mathrm{~V} \mid \mathrm{SHE}$, highlighting that at more negative potential the HER occurs to much larger extent. In the present work, different cathode potentials between $-0.30 \leq E \leq-0.01 \mathrm{~V} \mid \mathrm{SHE}$ and volumetric flow rates $\left(q\right.$, in $\mathrm{cm}^{3} \mathrm{~s}^{-1}$ ) have been tested. The mean linear flow velocity $(u$, in $\mathrm{cm} \mathrm{s}^{-1}$ ) is determined as $q / A_{\mathrm{T}} \varepsilon$, being $A_{\mathrm{T}}$ the transverse area wherein the electrolyte flows $\left(A_{\mathrm{T}}=B S\right.$, where $B$ and $S$ are the thickness and width of the channel, in $\mathrm{cm}$ ), and $\varepsilon$ is the overall voidage (dimensionless). The $\mathrm{H}_{2} \mathrm{O}_{2}$ content was determined on a Perkin-Elmer spectrophotometer from light absorption at $\lambda=408 \mathrm{~nm}[26]$.

\section{Results and discussion}

ig. 2a shows the $\mathrm{H}_{2} \mathrm{O}_{2}$ accumulation as a function of the electroly sis time under potentiostatic conditions at different applied cathodic potentials, namely $-0.01,-0.15,-0.20$ and $-0.30 \mathrm{~V} \mid \mathrm{SHE}$ at volumetric flow rate of $3.0 \mathrm{dm}^{3} \mathrm{~min}^{-1}\left(27.4 \mathrm{~cm} \mathrm{~s}^{-1}\right)$ for $180 \mathrm{~min}$. A greater accumulation was achieved at a given time as the applied potential was increased up to $-0.30 \mathrm{~V} \mid \mathrm{SHE}$, which is related to its quicker production from Eq. (1) resulting in current values between 0.13 and $0.20 \mathrm{~A}$ along the electrolysis. The application of more negative potential values does not enhance the $\mathrm{H}_{2} \mathrm{O}_{2}$ production, which can be explained by the occurrence of the parasitic HER [15].

Carbonaceous materials are suitable because the extent of HER at their surface is minimized, as confirmed up to the optimal value of $-0.30 \mathrm{~V} \mid$ SHE. This parasitic reaction is detrimental, since it causes a decrease in the current efficiency of the ORR to yield $\mathrm{H}_{2} \mathrm{O}_{2}$. Fig. $2 \mathrm{~b}$ and c shows the corresponding current efficiency and energy consumption, which were evaluated as described elsewhere [4]. The curves of Fig. 2b are in good agreement with the trends shown in Fig. 2a, with current efficiency increasing at more negative potentials up to $-0.30 \mathrm{~V} \mid \mathrm{SHE}$, because from that potential the reaction (1) is favored [15]. At that potential, the efficiency reached a maximum of $88 \%$ during the first hour of electrolysis; whereupon it decayed down to $67 \%$ at $180 \mathrm{~min}$. At more negative potentials than $-0.30 \mathrm{~V} \mid \mathrm{SHE}$, the HER becomes more relevant. The fact that the efficiency becomes lower than $100 \%$, even between -0.01 and $-0.30 \mathrm{~V} \mid \mathrm{SHE}$ where the HER is minimized, can be due partly to the potential distribution in the cathode matrix because part of the current is lost by capacitive phenomena as a result of its high volumetric area [27]. In addition, the use of an undivided cell favors the gradual oxidation of $\mathrm{H}_{2} \mathrm{O}_{2}$ to $\mathrm{O}_{2}$ at the anode surface, which is accompanied by the formation of $\mathrm{HO}_{2}{ }^{*}$ as an intermediate [4]. On the other hand, the efficiency loss as the electrolyses are prolonged can be due to the promotion of additional parasitic reactions up on solution recirculation. First, the electrochemical reduction at the cathode surface from Eq. (3) can occur to a certain extent, despite the fact that carbonaceous materials minimize this phenomenon. Second, disproportionation of $\mathrm{H}_{2} \mathrm{O}_{2}$ in the bulk via Eq. (4) also contributes to an eventual lower accumula- 
(a)

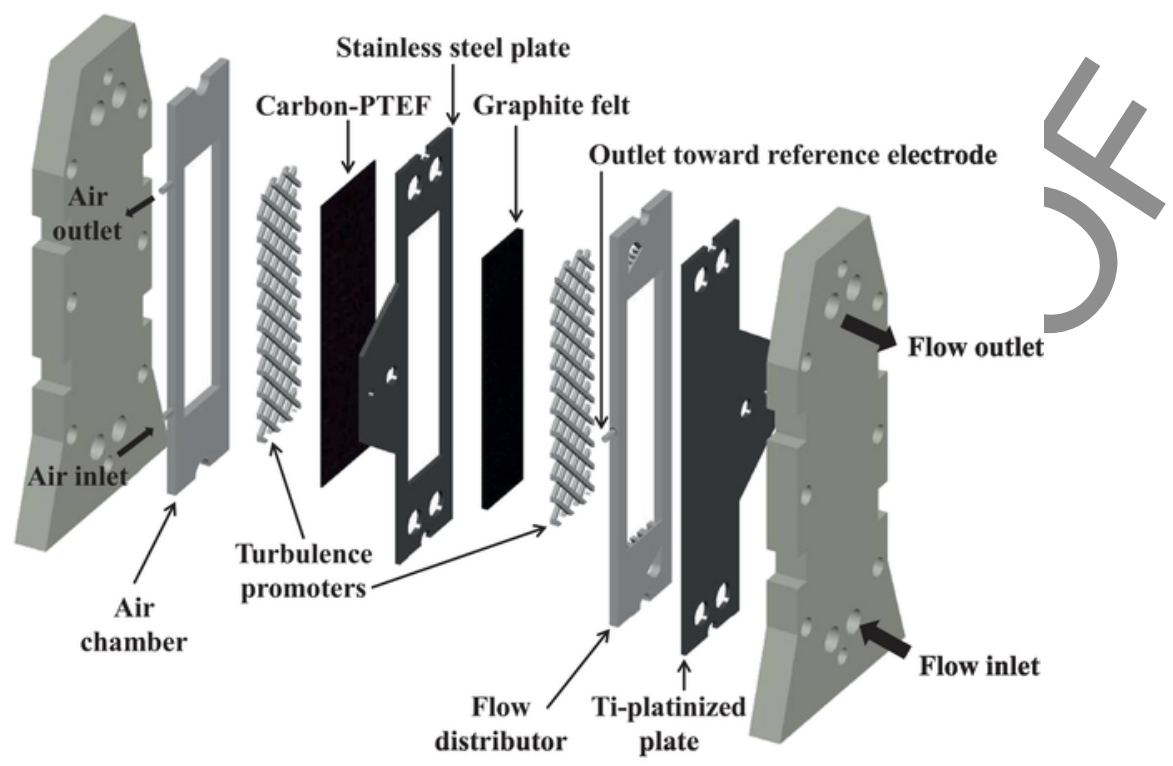

(b)

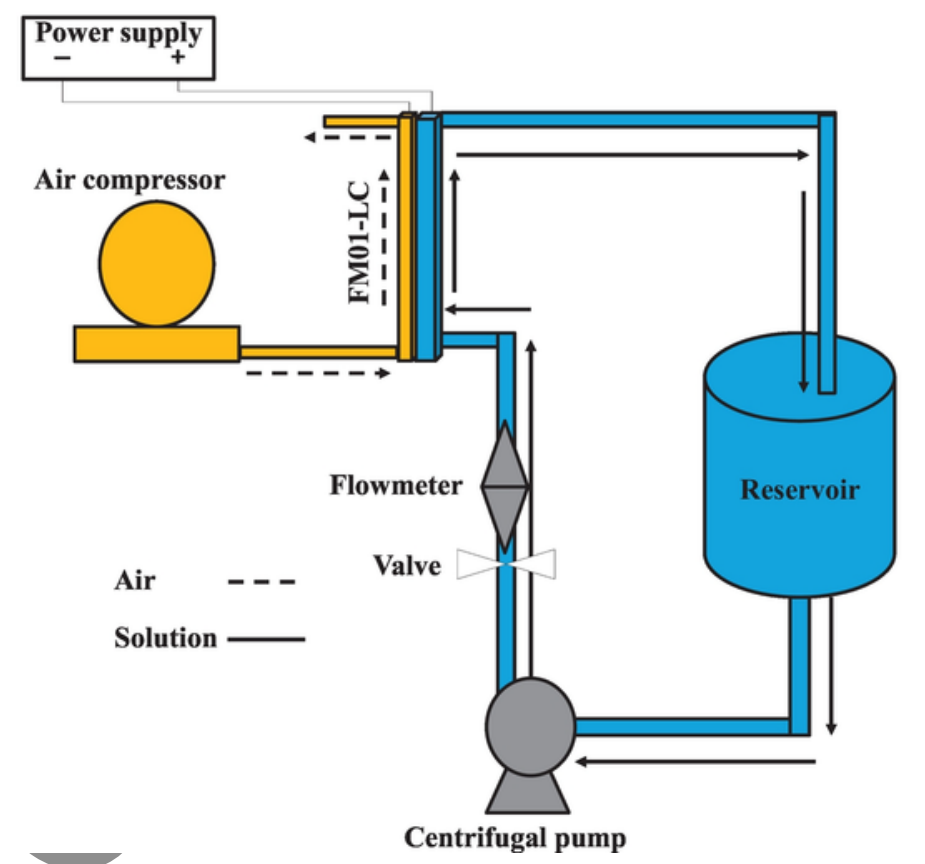

Fig. 1. (a) Exploded view drawing of the novelFM01-LC filter-press reactor. (b) Sketch of the recirculation pre-pilot plant.

tion than expected [4].

$$
\begin{aligned}
& \rightarrow 2 \mathrm{H}_{2} \mathrm{O} \\
& =1.800 \mathrm{~V}
\end{aligned}
$$$$
\mathrm{H}_{2} \mathrm{O}_{2}+2 \mathrm{H}^{+}+2 \mathrm{e}^{-}
$$

\section{SHE}

$$
2 \mathrm{H}_{2} \mathrm{O}_{2} \rightarrow \mathrm{O}_{2}+2 \mathrm{H}_{2} \mathrm{O}
$$

As can be observed in Fig. 2c, higher current efficiencies are correlated with lower energy consumptions, because of the gradual minimization of parasitic HER. Therefore, for the best condition (i.e., $E=-0.30 \mathrm{~V} v$ s. SHE), the energy consumption at the end of electroly sis was $5.4 \mathrm{kWh}\left(\mathrm{kg} \mathrm{H}_{2} \mathrm{O}_{2}\right)^{-1}$.

A second set of trials was performed to assess the effect of the liquid flow rate. It is well known that any electrochemical process that is limited by mass transport could be potentially improved by enhancing the hydrodynamics inside the cell. In this work, the oxygen from air pumped through the air chamber to reach the GDE is considered in excess $(0.7 \mathrm{~b}$ ar). The new cathode design offers a key advantage, in addition to feeding of the gaseous $\mathrm{O}_{2}$ at the exact place where it is consumed (typical in GDEs, in contrast to the approach based on air sparging in the solution bulk): the 3D porous graphite felt structure acts as gas disperser, which in turn may enhance the turbulence within the pores and plausibly improves the 


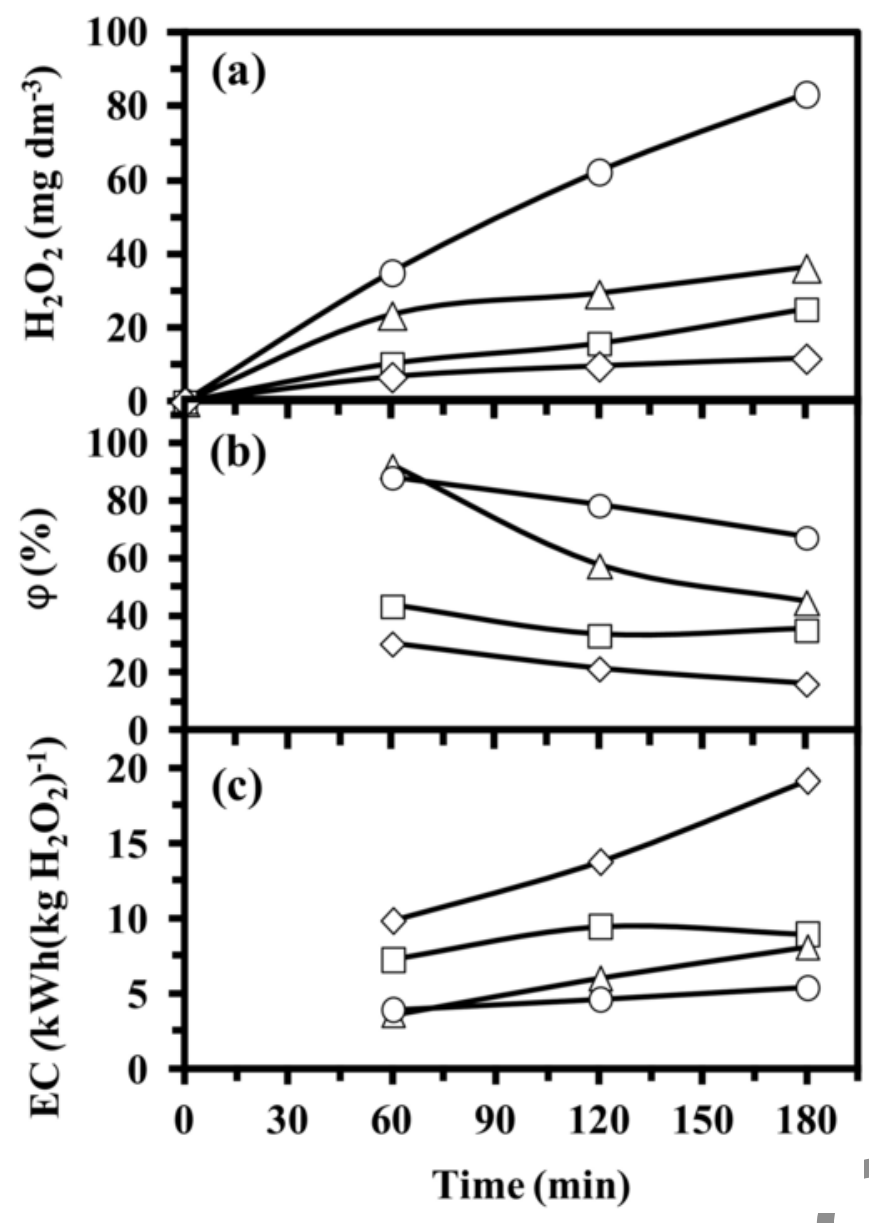

Fig. 2. (a) $\mathrm{H}_{2} \mathrm{O}_{2}$ concentration, (b) current efficiency and (c) energy con sumption per $\mathrm{kg} \mathrm{H}_{2} \mathrm{O}_{2}$ vs. time at different cathodic potentials: $(\diamond)-0.01$, $(\leq)-0.15,(\Delta)-0.20$, and $(O)-0.30 \mathrm{~V} v s$. SHE. Conditions: $4 \mathrm{dm}^{3}$ of $0.05 \mathrm{M}$ $\mathrm{Na}_{2} \mathrm{SO}_{4}$ solutions at $\mathrm{pH} 3.0$ and $u=27.4 \mathrm{cms}^{-1}$, with air fed at $0,7 \mathrm{bar}$.

mass transport [28]. Conversely, the concentration of protons in the bulk coming from a solution adjusted to $\mathrm{pH} 3.0\left(1 \mathrm{mMH}^{+}\right)$is certainly diluted and, consequently, the mass transport of these cations toward the cathode surface may limit the production of $\mathrm{H}_{2} \mathrm{O}_{2}$ from Eq. (1). Therefore, protons, which can be also transported once generated at the anode, could constitute the limiting reagent in the present system. Fig. 3a depicts the $\mathrm{H}_{2} \mathrm{O}_{2}$ accumulation as a function of the electrolysis time at different inflow velocities, namely 14.6, 21.0 , and $27.4 \mathrm{~cm} \mathrm{~s}^{-1}$ ( $q$ of $1.6,2.3$ and $3.0 \mathrm{dm}^{3} \mathrm{~min}^{-1}$ ), applying the optimal cathode potential $(-0.30 \mathrm{~V} v \mathrm{~s}$. SHE) for $240 \mathrm{~min}$. The curves suggest that an increase in the inflow velocity up to $27.4 \mathrm{~cm} \mathrm{~s}^{-1}$ leads to a greater $\mathrm{H}_{2} \mathrm{O}_{2}$ production from Eq. (1), attaining a maximum concentration of $100.4 \mathrm{mg} \mathrm{dm}^{-3}$ at $240 \mathrm{~min}$. This agrees with the progressive enhancement of the resulting current values as the velocity was increased, within the range of 0.20-0.26 A (for $u=14.6 \mathrm{cms}^{-1}$ ), $0.25-0.28 \mathrm{~A}$ (for $u=21.0 \mathrm{cms}^{-1}$ ) and $0.27-0.30 \mathrm{~A}$ (for $u=27.4 \mathrm{cms}^{-1}$ ). When the trials were prolonged for more than 240 min (not shown), the $\mathrm{H}_{2} \mathrm{O}_{2}$ concentration tended to reach a plateau, which can be mainly accounted for by the anodic destruction that leads to an equilibrium between the generation and destruction rates [4]. Furthermore, it is important to mention that velocities above $27.4 \mathrm{~cm} \mathrm{~s}^{-1}$ were not beneficial to attain a greater amount of $\mathrm{H}_{2} \mathrm{O}_{2}$. This means that, under these conditions, the hydrodynamics could not improve the mass transport inside the cell in an effective manner, probably be-

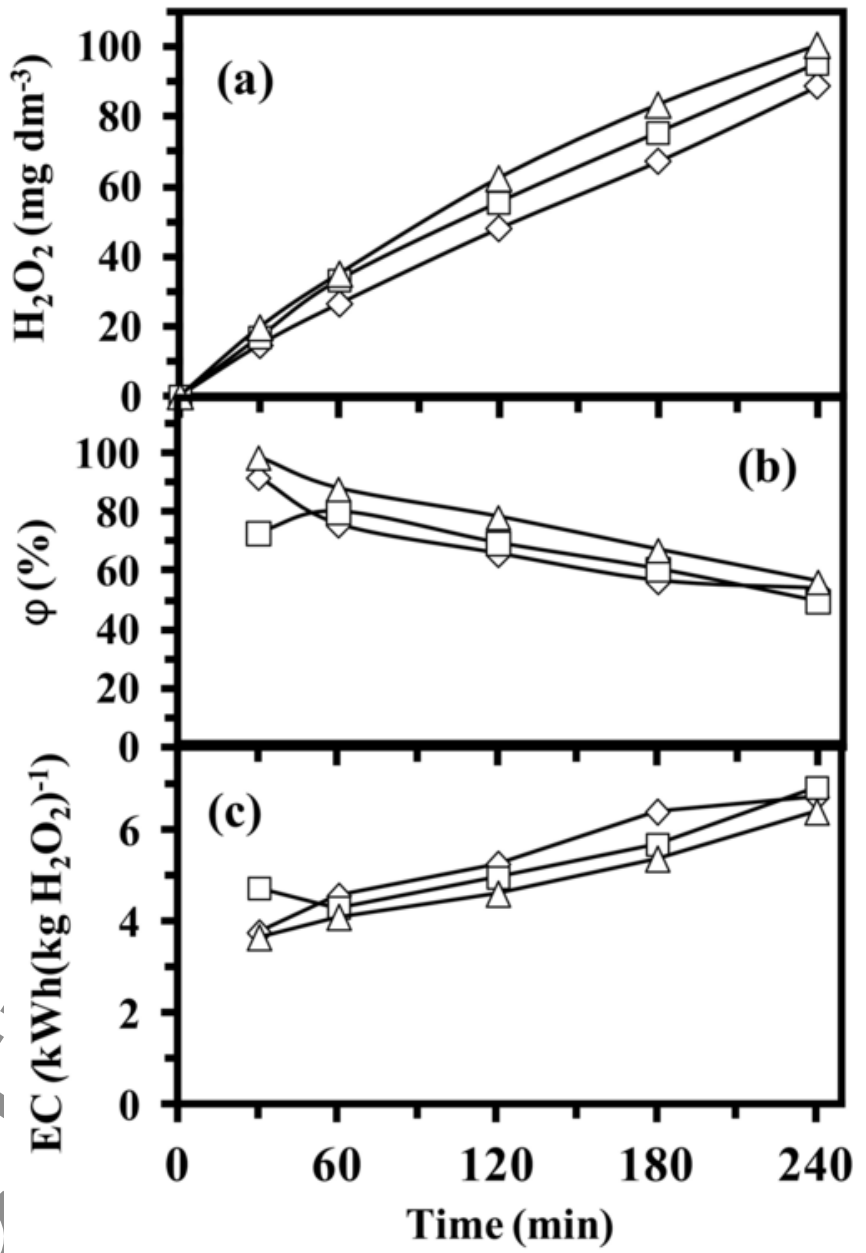

Fig. 3. (a) $\mathrm{H}_{2} \mathrm{O}_{2}$ concentration, (b) current efficiency and (c) energy consumption per $\mathrm{kg} \mathrm{H}_{2} \mathrm{O}_{2}$ vs. time at differ ent velocities: $(\diamond) 14.6,(\leq) 21.0$, and $(\Delta) 27.4 \mathrm{~cm} \mathrm{~s}^{-1}$. Conditions: as in Fig. 2 , at $-0.30 \mathrm{~V} v \mathrm{~s}$. SHE.

cause of: (i) excessive transport of protons toward the cathode surface, thus promoting the side HER over the ORR; (ii) faster transport of electrogenerated $\mathrm{H}_{2} \mathrm{O}_{2}$ toward the anode surface, thus increasing its destruction rate; (iii) a too short residence time of the electroly te solution within the reactor, limiting the participation of protons required for Eq. (1); and/or (iv) an increase in the hydraulic pressure that forces a greater penetration of the liquid phase into the porous electrode, which could change the area of the gas-solid-liquid interface, eventually enhancing the cathodic $\mathrm{H}_{2} \mathrm{O}_{2}$ destruction. In a previous paper employing the same pre-pilot plant but using just a graphite felt as cathode to produce $\mathrm{H}_{2} \mathrm{O}_{2}$ from dissolved $\mathrm{O}_{2}\left(8 \mathrm{mg} \mathrm{dm}^{-3}\right)$ in $0.050 \mathrm{moldm}^{-3} \mathrm{Na}_{2} \mathrm{SO}_{4}$ solution at $\mathrm{pH} 3$, a concentration of $50.3 \mathrm{mg} \mathrm{dm}^{-3} \mathrm{H}_{2} \mathrm{O}_{2}$ was attained at constant current density of $-0.16 \mathrm{mAcm}^{-2}$ and $17.6 \mathrm{cms}^{-1}$. This low conversion was attributed to the low concentration of dissolved oxygen [29].

Fig. $3 \mathrm{~b}$ and $\mathrm{c}$ shows the corresponding current efficiency and energy consumption per $\mathrm{kg}$ of $\mathrm{H}_{2} \mathrm{O}_{2}$ produced $v$ s. electrolysis time. The profiles shown in Fig. 3b agree with those of Fig. 3a and are very similar to those reported in Fig. $2 \mathrm{~b}$, suggesting the occurrence of the parasitic reactions, although the current efficiency was close to $100 \%$ after $30 \mathrm{~min}$ as a result of the enhanced hydrodynamics. The best electrolysis in terms of $\mathrm{H}_{2} \mathrm{O}_{2}$ production $\left(100.4 \mathrm{mg} \mathrm{dm}^{-3}\right.$ ) was achieved at constant cathode potential $E=-0.30 \mathrm{~V} \mid$ SHE and 
liquid flow rate of $27.4 \mathrm{~cm} \mathrm{~s}^{-1}$, giving rise to an energy consumption of $6.4 \mathrm{kWh}\left(\mathrm{kg} \mathrm{H}_{2} \mathrm{O}_{2}\right)^{-1}$ after 240 min of electroly sis.

\section{Conclusions}

This work demonstrates that $\mathrm{H}_{2} \mathrm{O}_{2}$ can be electrosynthesized in a pre-pilot plant using a modified, undivided filter-press FM01-LC reactor upon feeding of a cheap, purpose-made carbon cloth/ graphite felt cathode with compressed air, obtaining high current efficiencies at low energy consumptions. The experiments were performed at pH3.0 for future application in water treatment by Fenton-based electrochemical processes. The $\mathrm{H}_{2} \mathrm{O}_{2}$ production was optimal at $-0.30 \mathrm{~V}$, being enhanced as the mean linear flow velocity was increased from 14.6 to $27.4 \mathrm{~cm} \mathrm{~s}^{-1}$, owing to the enhanced mass transport of hydronium ions. This constitutes a first approach to efficiently produce $\mathrm{H}_{2} \mathrm{O}_{2}$ in a greener manner, although CFD simulations considering biphasic flow within the graphite felt will be needed.

\section{Acknowledgements}

Financial support from projects CTQ2016-78616-R (MINECO, Feder, EU) and 869/2016 (Universidad de Guanajuato, Mexico) and PhD scholarship No. 366128 (CONACyT) to G. Coria are acknowledged.

\section{References}

[1] R.L. Myers, The 100 Most Important Chemical Compounds: A Refer ence Guide, Green wood Press, Westport (CT), 2007.

[2] I. Sirés, E. Brillas, M.A. Otur an, M.A. Rodrigo, M. Panizza, Electrochemical advanced oxidation processes: to day and tomorrow, Environ. Sci. Pollut. Res. 21 (2014) 8336-8367.

[3] C.A. Huitle, M.A. Rodrigo, I. Sirés, O. Scialdone, Single and coupled electrochemical processes and reactors for the abatement of organic water pollutants: a critical review, Chem. Rev. 115 (2015) $13362-13407$.

[4] E. Brillas, I. Sirés, M.A. Oturan, Electro-Fenton process and rélated electrochemical technologies based on Fenton's reaction chemistry, Chem. Rev. 109 (2009) 6570-6631.

[5] C. Oloman, A.P. Watkinson, The electroreduction of oxygen to hy drogen peroxide on fluidized cathodes, Can. J. Chem. Eng. 53 (1975) 268-273.

[6] R.M. Reis, A.A.G.F. Beati, R.S. Rocha, M.H.M.T. Assumpção, M.C. Santos, R. Bertazzoli, M.R.V. Lanza, Use of gas diffusion electrode for the in situ generation of hydrogen peroxide in an electrochemical flow-by reactor, Ind. Eng. Chem. Res. 51 (2012) 649-654.

[7] J.M. Barazesh, T. Hennebel, J.T. Jasper, D.L. Sedlak, Modular advanced oxidation process enabled by cathodic hydrogen peroxide production, Environ. Sci. Technol. 49 (2015) 7391-7399.

[8] X. Yu, M. Zhou, G. Ren, L. Ma, A novel dual gas diffusion electrodes system for efficient hydrogen peroxide generation used in electroFenton, Chem. Eng. J. 263 (2015) 92-100.

[9] E. Bocos, E. Brillas, M.A. Sanromán, I. Sirés, Electrocoagulation: simply a phase separation technology? The case of bronopol compared to its treatment by EAOPs, Environ. Sci. Technol. 50 (2016) $7679-7686$.

[10] S. Lanzalaco, I. Sirés, M.A. Sabatino, C. Dispenza, O. Scialdone, A. Galia, Synthesis of polymer nanogels by electro-Fenton process: in- vestigation of the effect of main operation parameters, Electrochim. Acta 246 (2017) 812-822.

[11] W. Li, A. Bonakdar pour, E. Gynge, D.P. Wilkinson, Drinking water purification by electrosynthesis of hydrogen peroxide in a powerproducing PEM fuel cell, ChemSusChem 6 (2013) 2137-2143.

[12] Y. Liang, Y. Li, H. Wang, H. Dai, Strongly coupled inorganic/ nanocarbon hybrid materials for advanced electrocatalysis, J. Am. Chem. Soc. 135 (2013) 2013-2036.

[13] A. Ver daguer-Casadevall, D. Deiana, M. Kar amad, S. Siahrostami, P. Malacrida, T.W. Hansen, J. Rossmeisl, I. Ghorkendorff, I.E.L. Stephens, Trends in the electrochemical synthesis of $\mathrm{H}_{2} \mathrm{O}_{2}$ : enhancing activity and selectivity by electrocatalytic site engineering, Nano Lett. 14 (2014) 1603-1608.

[14] A. Dirany, I. Sirés, N. Oturan, A. Özcan, M.A. Oturan, Electrochemical treatment of the antibiotic sulfachloropyridazine: kinetics, reaction pathways, and toxicity evolution, Environ. Sci. Technol. 46 (2012) 4074-4082.

[15] G. Coria, T. Pérez, I. Sirés, J.L. Nava, Mass transport studies during dissolved oxygen reduction to hydrogen peroxide in a filter-press electrolyzer using graphite felt, reticulated vitreous carbon and boron-doped diamond as cathodes, J. Electroanal. Chem. 757 (2015) 225-229.

[16] F. Yu, M. Zhou, X. Yu, Cost-effective electro-Fenton using modified graphite felt that dramatically enhanced on $\mathrm{H}_{2} \mathrm{O}_{2}$ electro-generation without external aeration, Electrochim. Acta 163 (2015) 182-189.

[17] K.V. Plakas, A.J. Karabelas, S.D. Sklari, V.T. Zaspalis, Tow ard the development of a novel electro-Fenton system for eliminating toxic organic substances from water. Part 1 . In situ generation of hydrogen peroxide, Ind. Eng. C hem. Res. 52 (2013) 13948-13956.

[18] X. Zhang, J. Fu, Y. Zhang, L. Lei, A nitrogen functionalized carbon nanotube cathode for highly efficient electrocataly tic generation of $\mathrm{H}_{2} \mathrm{O}_{2}$ in Electro-Fenton system, Sep. Purif. Technol. 64 (2008) $116-123$.

[19] Y. Liu, X. Quan, X. Fan, H. Wang, S. Chen, High-yield electrosyn thesis of hydrogen peroxide from oxygen reduction by hierarchically porous carbon, Angew. Chem. Int. Ed. 54 (2015) 6837-6841.

[20] T.X.H. Le, M. Bechelany, S. Lacour, N. Oturan, M.A. Oturan, M. Cretin, High removal efficiency of dye pollutants by electron-Fenton process using a graphene based cathode, Carbon 94 (2015) $1003-1011$.

[21] O. González Pérez, J.M. Bisang, Electrochemical synthesis of hydrogen peroxide with a three-dimensional rotating cylinder electrode, J. Chem. Technol. Biotechnol. 89 (2014) 528-535.

J.F. Pérez, J. Llanos, C. Sáez, C. López, P. Cañizares, M.A. Rodrigo, Electrochemical jet-cell for the in-situ generation of hydrogen peroxide, Electrochem. Commun. 71 (2016) 65-68.

[23] O. Scialdone, A. Galia, C. Gattuso, S. Sabatino, B. Schiavo, Effect of air pressure on the electrogeneration of $\mathrm{H}_{2} \mathrm{O}_{2}$ and the abatement of organic pollutants in water by electro-Fenton process, Electrochim. Acta 182 (2015) 775-780.

[24] F.F. Rivera, C. Ponce de León, F.C. Walsh, J.L. Nava, The reaction environment in a filter-press laboratory reactor: the FM01-LC flow cell, Electrochim. Acta 161 (2016) 436-452.

[25] E. Brillas, J.C. Calpe, J. Casado, Mineralization of 2,4-D by advanced oxidation processes, Water Res. 34 (2000) 2253-2262.

[26] F.J. Welcher (Ed.), Standard Methods of Chemical Analy sis, 6 th ed., vol. 2, Part B, R.E. Krieger Publishers, Huntington, New York, 1975.

[27] J.L. Nava, A. Recéndiz, L.G. González, G. Carreño, F. Martínez, Mass transport and potential studies in a flow-through porous electrode reactor. A comparative study of reticulated vitreous carbon and graphite felt used as cathode, Port. Electrochim. Acta $27(2009)$ 381-396.

[28] L.F. Castañeda, F.C. Walsh, J.L. Nava, C. Ponce de León, Grafite felt as a versatile electrode material: properties, reaction environment, performance and applications, Electrochim. Acta 258 (2017) 1115-1139.

[29] T. Pérez, I. Sirés, E. Brillas, J.L. Nava, Solar photoelectro-Fen ton flow plant modeling for the degradation of the antibiotic erythromycin in sulfate medium, Electrochim. Acta 228 (2017) 45-56. 